\title{
Cultural learning through drama tasks: An action research approach
}

\section{Almut Küppers}

Anja Jäger (2011): Kultur szenisch erfahren. Interkulturelles Lernen mit Jugendliteratur und szenischen Aufgaben im Fremdsprachenunterricht. Frankfurt/Main et al.: Peter Lang ISBN 978-3-631-61155-5

\section{Research on cultural learning}

Teaching a language is a complex endeavor. Promoting cultural learning seems to be an even more sophisticated teaching challenge. The question of how to research multilayered processes of subtle cultural learning in a foreign language classroom setting has not yet been adequately answered - much rather (and despite DESI) it still remains an unexplored island in what appears to be a much more cultivated land, namely that of foreign language research. In her study "Kultur szenisch erfahren" Anja Jäger has opted for a research design which sets out to explore intercultural learning from the inside out as a teacher-researcher. The author is a middle school teacher herself who has had a number of years of teaching experience under her belt, before she embarked on an action research project. Anja Jäger, thus, knew the field under investigation very well when she started to illuminate the following questions: Which kind of drama tasks are especially suitable in order to develop intercultural communicative competences in English foreign language learners and under which teaching conditions do the tasks unfold their potential most effectively (p. 13)?

\section{Research focus: Drama tasks based on a literary text}

The starting point for Anja Jäger's study is the undisputable realization that the teaching aims for the foreign language subjects stand in clear opposition to current teaching practice: Intercultural communicative competences are carved in stone through the claims by the Common European Framework of References for Languages as well as the German Bildungsstandards and German core curricula. However, teachers feel left alone with these high demands as there is a clear lack of tasks which promote intercultural learning, not to mention the lack of empirical evidence for what kind of tasks successfully do the trick. Documented teaching practice (not least in many contributions of Scenario) gives rise to the assumption that drama work works when aiming 
to foster intercultural learning in the foreign language classroom. Both fields share much of a common ground: holistic learning and the performative dimension of language in communication. Hence, for her study Anja Jäger developed an interdisciplinary theoretical framework which integrates various aspects of foreign language teaching methodology, and combines them with drama teaching approaches and the Task-based Approach (TBA).

Theoretical considerations begin with an account of the overarching concept of intercultural learning (pp. 15-58) and its relevance for teaching and learning a foreign language. Michael Byram's (1997) prominent model of Intercultural Communicative Competence (ICC) serves as an anchorage for the development of the overall research design. Likewise, TBA is an important reference point in the study, as it provides the theoretical underpinnings for the actual drama tasks devised (pp. 59-86). Jäger calls the set of tasks she developed for the research project task-as-workplan. Task-as-workplan is not seen as static teaching entity but as a starting point for what is called task-in-process; in other words, the first set of drama tasks are meant to be refined, changed and by so doing enhanced in the process of the developing research project by all research partners, i.e. teachers, learners and the research leader respectively. It is evident already that a research design based on the principles of "change" and "openness" is a particular challenging one. Two other sources of inspirational input have been used for the development of the underlying theory as well as for the mapping of the research / drama tasks. Both of them have had quite an impact on foreign language teaching methodology lately: One is the field of Literaturdidaktik (pp. 87-118) - more precisely, teaching teenage fiction in combination with creative tasks - the other field is that of theater pedagogy or drama in education, and here the works of two of the most prominent German protagonists (Manfred Schewe and Ingo Scheller) play an important role (pp. 119-148). The rationale for the text basis Jäger chose for her study seems to be well thought-through and convincing, too: Bend it like Beckham belongs to the genre of British fiction of migration and depicts the situation of a British teenage girl of Indian heritage who experiences a conflict with her family when she secretly starts to play football. Hence, the conflict is partly rooted in the opposing concepts of tradition vs. modernity and is partly a classical generation problem (pp. 150-158).

\section{The research setting: German middle school classes}

The author sets out to explore the effect of drama tasks for the development of intercultural communicative competences in three different research cycles carried out in two year 9 and one year 10 class at two middle schools. Given that the study was a $\mathrm{PhD}$ project, an impressive variety of research methods was employed (cf. chapter 7: research methodology pp. 159-202): Research diaries were kept by everybody involved in the research project (except the learners); audiotapes of group work phases were taken; videotapes of the teaching / classroom situation were produced and transcribed; field notes were 
taken by co-researching students from Fribourg University of Education based on observation charts; a standardized final questionnaire was filled out by all participating learners; and finally, interviews with teachers and learners were carried out based on a partly structured manual of pre-prepared questions ${ }^{1}$. The author herself taught in the first research cycle with the English teacher of the year 9 class as a participating observer. The second cycle was taught in a year ten by their English teacher and the last cycle was again taught in a year 9 at the same school, this time by a (male) English teacher. The size of group of students who assisted as observers in the field varied from cycle to cycle. In sum, Anja Jäger worked with changing partners in a research team and allied forces in a cooperative research setting which means a community of experts was established for each research cycle with the aim to support, supervise, inspire and correct each other. Naturally, a dynamic and open research process bears the risk that complexity is skyrocketing and hard to control. On the other hand, it clearly has the advantage that research is not imposed onto the field / the subjects and that the research process is constantly monitored and validated from within the community of experts. Moreover, generated research data was never interpreted by the author alone, but subjected to a complex process of negotiation of meaning in which all partners took part, discussing and evaluating video-scenes, transcripts, observation notes and peer views against the set of theoretical categories (on ICC) laid out before entering the field (cf. 182 ff.).

It is especially illuminating to see how challenging it was for the research team to translate a vibrant, lively classroom situation which encapsulates an unfolding process of creative work into linguistic data confined to print (189 ff.). With the research focus on ICC, it seemed logical to videotape classroom scenes in order to capture the bodily (performative) dimension intercultural learning inevitable entails. However, since "actions speak louder than words", written transcripts based on videotapes cannot be more than an impoverished translation of what used to be reality (cf. Dörnyei 2007: 246). The transformation into data results in a loss of authenticity which might be acceptable for a language research projects. A project aiming to explore cultural learning is facing a core dilemma at this point: How can the performative dimension of the generated data be preserved when the research focus is exactly this: performativity? The research team around Anja Jäger decided to paraphrase the performative dimension of their data in terms of "Körpersprachebeschreibungen" (p. 190). Describing facial expressions, gestures, or (eye-) movements is - for the time being - surely a legitimate compromise - but not a way out of the dilemma. It is to be hoped that with the growing importance of computer support, the future of research on performativity will bring about new electronic forms of presenting data and

\footnotetext{
${ }^{1}$ It would have been helpful for further research activities and also for a communicative validation by the readership if the research instruments like the observation charts, the interview guidelines, or an example transcript would have been included in the appendix of the printed version of the thesis. However, the author will upload the research instruments and other materials on the following website: http://www.interkulturelles-lernen.eu
} 
research results e.g. as video-essays and video-reports.

\section{Research findings: Selected reflections}

The core chapter of the study report (no. 8) comprises some 130 pages and is by far the longest as it contains the research findings (pp. 203-337). Depending on the reader perspective, of course, this chapter is the most exciting one in study reports: It's the place where the author reaps the fruits of years of research and hard labor. Anja Jäger begins with an overview of the seven drama tasks which were used in the three research cycles (BILB 1, BILB 2, BILB 3) ${ }^{2}$. All tasks are presented in graphs which nicely illustrates the progression from BILB 1 to BILB 3 as all task changes are easily recognizable against the categories "purpose", "product", "procedure" and "reason/s for changes" (p. $203 \mathrm{ff}$.). It is noticeable that all of the drama tasks are demanding in terms of complexity (of the task and the theme), group dynamics and emotional involvement (e.g. racism) as most of them are role plays or improvisations of key scenes with one sculpturing task amongst them. For various reasons, the author / research team decided to present the transformation of one particular drama task in detail. The task in question is based on a key-scene of the story "Joe at the Bhamras' house" and was originally conceptualized as a role-play in BILB $1+2$ and developed into an improvisation in BILB 3. Hence, the most sophisticated king-discipline of drama work (cf. Johnstone 2007) - the improvisation - was pushed to the centre of the study-report. Surprisingly, the theory-base to discuss the findings of the study against the potential of this powerful drama convention is extremely slim. Much research data was, however, fed into the description of each teaching cycle and it is very insightful to track the follow-up changes from cycle to cycle. Each cycle is concluded with a critical analysis which serves as a rationale for the task-refinements. It is also notable that the research team was not too happy with the quality of work in the first two c ycles. The change from role-play to improvisation is not least of all a decision triggered by the realization that there was hardly any body language visible in the role-plays, mostly due to the fact that learners read their roles from papers. The improved drama task in BILB 3 , an improvisation, was a more authentic communicative situation in which language was produced more spontaneously and, thus, made it necessary to give the learners more language support.

In the final part of the chapter, Jäger discusses the teaching conditions which help to develop the ICC-potential of drama tasks. However, these findings do not come as a surprise for practitioners who work in the field of theatre pedagogy or drama education. Drama work experience clearly shows that the essential factor in the drama process is - first and foremost - the teacher and his/her skills to create an atmosphere of trust and group-spirit as well as an "as-if" situation, clear instructions, the warm-up phase and physical readiness of all participants,

\footnotetext{
${ }^{2}$ BILB stands for Bend it like Beckham; the order is chronological, BILB 3 is, thus, the last research cycle.
} 
further input to challenge stereotyping, and the quality of reflection, to name but a few. The drama setting with its time-frame and space options is certainly also important but secondary as are props or costumes. Now, what is it that's necessary to unlock the potential of drama tasks for intercultural learning? Anja Jäger's study clearly supports the following: Neither is a seemingly suitable text base (e.g. fiction of migration) a guarantee for intercultural learning nor does a drama task like an improvisation automatically foster ICC. What is essential for high quality intercultural learning processes is an awareness (which is actually a common place) on the part of the teacher as well as learners that communication is culture-bound and has a performative dimension which is expressed through body-language, gestures, mimic, facial expressions etc. This must be the dramatic focus point in a drama unit on ICC in all its phases and all teaching decisions have to be made accordingly. Anja Jäger's research cycle shows that learners are very well able to slip into the shoes of another person from a different cultural background and they can adopt those roles and play them convincingly without accepting their positions - but only when they are provided with enough support: socio-cultural background knowledge (e.g. on traditions and customs), body language support (e.g. greeting procedures, how to express politeness etc.) and language support (cf. 344-345ff.).

Finally, the study also clearly shows the difficulties a teacher encounters when a drama unit is based on a novel - which means a long text for middle-school learners. Some of the drama tasks heavily relied on the reading assignments (partly to be done at home) which some of the learners never accomplished. Consequently, those students were only able to scratch the surface when confronted with some of the complex drama tasks and running the risk of reproducing stereotypes. This is not meant to be an argument against reading novels in foreign language classrooms, quite the opposite is surely advisable. But it does question the added-value of a drama unit based on a novel when the focus is put on ICC. Instead of struggling with a long reading phase, keeping a reading log and constantly revising "what has happened before", I would much rather recommend to use a selected critical incident of the story - in this case the scene in the Bhamras house. The critical incident could be contextualized by a storyline (on two or three pages) or by a teacher-in-role convention and socio-cultural background information added and a lot more time would be available for the actual work on ICC and the exploration and experimentation of the various perspectives and physical dimensions in this conflict.

\section{Research as intercultural communication}

The study report, which was published in 2011 and which is based on the author's $\mathrm{PhD}$ thesis from 2009, is certainly a treasure trove from a research methodological point of view as it allows the reader to gain an insight into the complex structure of the fragile action research process. Naturally, research reports seem to be the opposite of what is characteristic for the underlying research processes: The final text is just the tip of an iceberg. It always 
looks neat, it is two-dimensional and well structured, and seems to give evidence of a logical order of research decisions which are theory-based and well-planned months beforehand. So it seems. In contrast, research reality often looks very different especially when the research setting is a qualitative one and aims to explore a field or s et of $\mathrm{q}$ uestions: Research p rocesses are complex, multidimensional, they entail numerous communicative challenges and decision making moments appear out of the blue and their consequences are often unpredictable. In a nutshell: Research is messy! It is one of the merits of this study report that within its physical boundaries of some 370 pages, the demanding research process becomes transparent and is not looked at through rose-colored glasses and presented in sparkling research prose only. Anja Jäger frankly and self-critically addresses (personal) stumbling blocks and communicative hick-ups she encountered in the self-chosen research setting in the South of Germany. Embarking on a research project, and even more so, being part of it as a teacher-researcher in an action research setting, means to move into a system of unknown coordinates which needs to be managed with a highly developed sensitivity for pitfalls and potentials alike: As a project leader one needs to relate to the various persons involved in the project, here namely: the co-teachers, the middle-school learners and the university students - all of them with their various expectations, skills and needs. Driven by research questions and theoretical background knowledge and influenced by changing communicative needs in the research context as well as the necessity to adjust the research situation accordingly, the project leader certainly needs skills of interaction and discovery. And as a precondition of all this, constantly coordinating the various research perspectives and emphatically managing the vast amount of data afterwards is finally essential for the success of the project. All this leads to the assumption that Anja Jäger must be a very communicative and interculturally competent researcher herself! Moreover, the report also proves that and open, dynamic action research design is appropriate for an open and dynamic research subject like drama work. Finally the text meets the high demands (not only of transparency) in qualitative research and can, thus, be seen as a valuable contribution to the methodological discussion of how action research projects can be carried out in a challenging school environment. As an inspiring research read I would recommend it to anyone interested in action research and any teacher who has been toying around with the idea to action research his / her own teaching. Anja Jäger's insights might get the ball going. Despite some minor shortcomings (e.g. orientation is hard in the chapter on the research findings), this s tudy is c ertainly inspiring for a nyone generally interested in drama tasks and the question how to implement them in order to enhance teaching for intercultural learning. 


\section{Bibliography}

Dörnyei, Zoltán (2007): Research Methods in Applied Linguistics. Quantitative, Qualitative and Mixed Methodologies. Oxford: Oxford University Press Johnstone, Keith (2007): Impro. Improvisation and the Theatre. An Inspirational Sourcebook for Boosting Creativity ( $1^{\text {st }}$ ed. 1979). London: Methuen 